\title{
Influence of rhizobacterial volatiles on the root system architecture and the production and allocation of biomass in the model grass Brachypodium distachyon (L.) P. Beauv.
}

Pierre Delaplace ${ }^{1 *}$, Benjamin M. Delory ${ }^{1}$, Caroline Baudson ${ }^{1}$, Magdalena Mendaluk-Saunier de Cazenave ${ }^{1}$, Stijn Spaepen ${ }^{2}$, Sébastien Varin ${ }^{1}$, Yves Brostaux ${ }^{3}$ and Patrick du Jardin ${ }^{1}$

\begin{abstract}
Background: Plant growth-promoting rhizobacteria are increasingly being seen as a way of complementing conventional inputs in agricultural systems. The effects on their host plants are diverse and include volatile-mediated growth enhancement. This study sought to assess the effects of bacterial volatiles on the biomass production and root system architecture of the model grass Brachypodium distachyon (L.) Beauv.

Results: An in vitro experiment allowing plant-bacteria interaction throughout the gaseous phase without any physical contact was used to screen 19 bacterial strains for their growth-promotion ability over a 10-day co-cultivation period. Five groups of bacteria were defined and characterised based on their combined influence on biomass production and root system architecture. The observed effects ranged from unchanged to greatly increased biomass production coupled with increased root length and branching. Primary root length was increased only by the volatile compounds emitted by Enterobacter cloacae JM22 and Bacillus pumilus T4. Overall, the most significant results were obtained with Bacillus subtilis GB03, which induced an $81 \%$ increase in total biomass, as well as enhancing total root length, total secondary root length and total adventitious root length by $88.5,201.5$ and $474.5 \%$, respectively.
\end{abstract}

Conclusions: This study is the first report on bacterial volatile-mediated growth promotion of a grass plant. Contrasting modulations of biomass production coupled with changes in root system architecture were observed. Most of the strains that increased total plant biomass also modulated adventitious root growth. Under our screening conditions, total biomass production was strongly correlated with the length and branching of the root system components, except for primary root length. An analysis of the emission kinetics of the bacterial volatile compounds is being undertaken and should lead to the identification of the compounds responsible for the observed growth-promotion effects. Within the context of the inherent characteristics of our in vitro system, this paper identifies the next critical experimental steps and discusses them from both a fundamental and an applied perspective.

\footnotetext{
* Correspondence: pierre.delaplace@ulg.ac.be

'University of Liège, Gembloux Agro-Bio Tech, Plant Biology, Passage des Déportés 2, 5030 Gembloux, Belgium

Full list of author information is available at the end of the article
} 


\section{Background}

Within the crop environment, both rhizospheric (underground) and phyllospheric (aboveground) bacteria greatly influence plant growth [1-3]. Free-living, biofilm-forming and root-colonizing rhizobacteria have therefore been considered as possible inoculants for increasing plant productivity and improving nutrient-use efficiency $[4,5]$.

Plant growth-promoting rhizobacteria (PGPR) can have complex effects on their host plants. The underlying mechanisms include; (1) root system architecture (RSA) modulation and increased shoot growth, mediated particularly by indole-3-acetic acid, cytokinins, gibberellins, salicylic acid, ethylene and brassinosteroids; (2) phosphate solubilisation; (3) free nitrogen fixation; (4) suppression of harmful microorganisms; (5) induced systemic resistance; and (6) induced systemic tolerance of abiotic constraints $[1-4,6,7]$.

Among these interaction mechanisms, the emission of bacterial volatile organic compounds (VOCs) has been shown to promote plant growth [6] and VOCmediated plant growth modulation is now widely considered to be an important mechanism [8]. Apart from inorganic molecules such as $\mathrm{CO}_{2}, \mathrm{CO}, \mathrm{H}_{2}, \mathrm{~N}_{2}, \mathrm{~N}_{2} \mathrm{O}$, $\mathrm{NO}, \mathrm{NO}_{2}, \mathrm{NH}_{3}, \mathrm{H}_{2} \mathrm{~S}$ and $\mathrm{HCN}$, microorganisms are able to emit VOCs [5, 9-11]. These include acids, alcohols, ketones, aldehydes, esters, terpenoids, aromatic, nitrogenous and sulphurous compounds, and ethylene $[7,12,13]$. Among these compounds, although 300 candidate molecules have been identified to date, very few have been unequivocally identified as being responsible for the observed change in plant growth $[8,9]$, mainly because bacterial volatiles can act as individual compounds or in mixtures [13].

Bacterial volatile exposure can lead to an increase in plant biomass (up to sixfold) or to plant death after 21 days of the exposure of Arabidopsis thaliana (L.) Heynh to bacterial volatiles $[8,11]$. In general, the positive effects of bacterial VOCs on plant growth have been less frequently documented than the negative ones $[8,14]$. On the positive side, eight bacterial volatiles (2,3-butanediol, 3-hydroxy-2butanone, 2-pentylfuran, N,N-dimethyl-hexadecanamine, $\mathrm{CO}_{2}$, 13-tetradecadien-1-ol, 2-butanone and 2-methyl-n-1tridecene) have been shown to promote plant growth $[6,8$, 15-19]. Short-term growth-promotion effects observed on the model plant, A. thaliana, exposed to Bacillus subtilis GB03 volatiles include: (1) modulations of cytokinin [6], ethylene [20, 21], auxin, salicylic acid, brassinosteroids, gibberellins [4], abscisic acid and jasmonic acid [21] signalling pathways; (2) higher photosynthetic capacity, chloroplast number, chlorophyll content, starch accumulation and iron uptake [22]; (3) increased tolerance of osmotic, salt and drought stress through the accumulation of choline and glycine betaine in plant tissues [23, 24]; (4) reduced severity of disease symptoms; (5) reduced sensitivity to reactive oxygen species [25]; and (6) increased resistance against pathogens [13]. Similar long-term effects have been described [26] and for other plant species, such as Nicotiana benthamiana Karel Domin [27, 28] and Agrostis stolonifera L. [11, 29].

On the other hand, neutral or negative effects of rhizobacterial volatiles have been noted on plants, fungi and pathogenic bacteria $[14,30]$. Hydrogen cyanide, which is produced by a small number of bacterial species including Pseudomonas [10] and Chromobacterium species, might be responsible for their negative impact on wheat. Complementarily, the negative effects of Serratia species on A. thaliana have been ascribed to dimethyl disulphide, $\beta$-phenyl-ethanol and the inorganic volatile $\mathrm{NH}_{3}$ $[8,13,18,31]$.

Despite these studies, several questions remain unanswered and need to be addressed. So far, only two studies on the impact of rhizobacterial volatiles on grass growth have been published. The observed effects were negative [32] or non-significant [30]. Until now, therefore, no clear growth-promotion effect of bacterial volatiles on Poaceae has been demonstrated. The root system development of members of the grass family differs in overall architecture and in the anatomy of individual roots [33], which could result in volatile effects that are different from those known with A. thaliana (Monocots $v s$ Dicots, respectively).

With regard to RSA measurements, most in vitro studies use horizontal Petri dishes in which roots are grown in the agar plate, thus limiting their exposure to water-soluble volatile compounds. In addition, few studies have sought to characterise microbial volatilemediated RSA modification using a dedicated experimental set-up [7, 13, 18, 34]. The few results that do exist suggest that bacterial VOCs are able to modulate root system morphogenic processes and that these RSA modifications could be related to biomass production $[7,13]$.

The aim of this study was to investigate the impact of bacterial volatile compounds on the biomass production and RSA of Brachypodium distachyon (L.) Beauv. (line Bd21), based on a 10-day in vitro co-cultivation. The genus Brachypodium is phylogenetically close to the temperate cereal genera Triticum, Hordeum and Avena in the subfamily Pooideae $[35,36]$ and it is now considered to be a promising model genus for studying root system development in cereals and the impact on plant yield [37, 38]. In this study we sought to answer the following questions: What are the main plantlet phenotypes induced by bacterial volatiles? Based on the biomass production and RSA results in our screening system, which strains have the most significant effect? How do the observed effects differ from those reported for dicotyledonous plants such as $A$. thaliana? The results 
are discussed within the context of the potential and limits of the in vitro system used in the study.

\section{Results}

\section{Characteristics of the in vitro co-cultivation system}

In order to expose $B$. distachyon $\mathrm{Bd} 21$ plantlets to bacterial volatile compounds and assess their effects on biomass production while measuring RSA parameters, a near-vertical co-cultivation system was set up (Fig. 1). The bacterial growth media was based on the work of [15] and its composition was a compromise between a minimal medium and a nutrient one. The plants were grown on an agar plate containing Hoagland's medium, which was physically separated from the bacteria, but shared the same atmosphere. The plantlets could be maintained in this system at $22{ }^{\circ} \mathrm{C}$ for up to 10 days. The leaves and roots grew on top of the agar plate and were therefore exposed to bacterial volatiles, whatever their polarity or solubility in the agar. Three kinds of roots were potentially produced by the plantlets: a primary root $(\mathrm{PR})$, secondary roots $(\mathrm{SR}$, branching from the $\mathrm{PR}$ ) and adventitious roots (AR, Fig. 1). These three types of roots correspond to the 'primary seminal axile root', the 'branch roots' and the 'coleoptile nodal roots' defined by [39]. This experimental set-up did not induce any gradient effects because all the plantlets were positioned at the same distance from the source of the volatile compounds.

\section{Principal component analysis (PCA) and strain clustering}

Fourteen variables were measured on the $B$. distachyon plantlets after 10 days of volatile compound-based interactions with each of the 19 bacterial strains (Figs. 4 and 5, Additional file 1: Figure S1). In order to group the strains in terms of their growth-modulation ability, a PCA was performed on the dataset based on weighted and reduced variables (Fig. 2). This processing enabled us to assign the same weight for biomass- or RSArelated variable classes. Within each class, each variable had the same weight, irrespective of its order of magnitude. The 14 principal components (PCs) were then used as input variables to cluster the strains based on the Euclidian distance and the Ward algorithm.
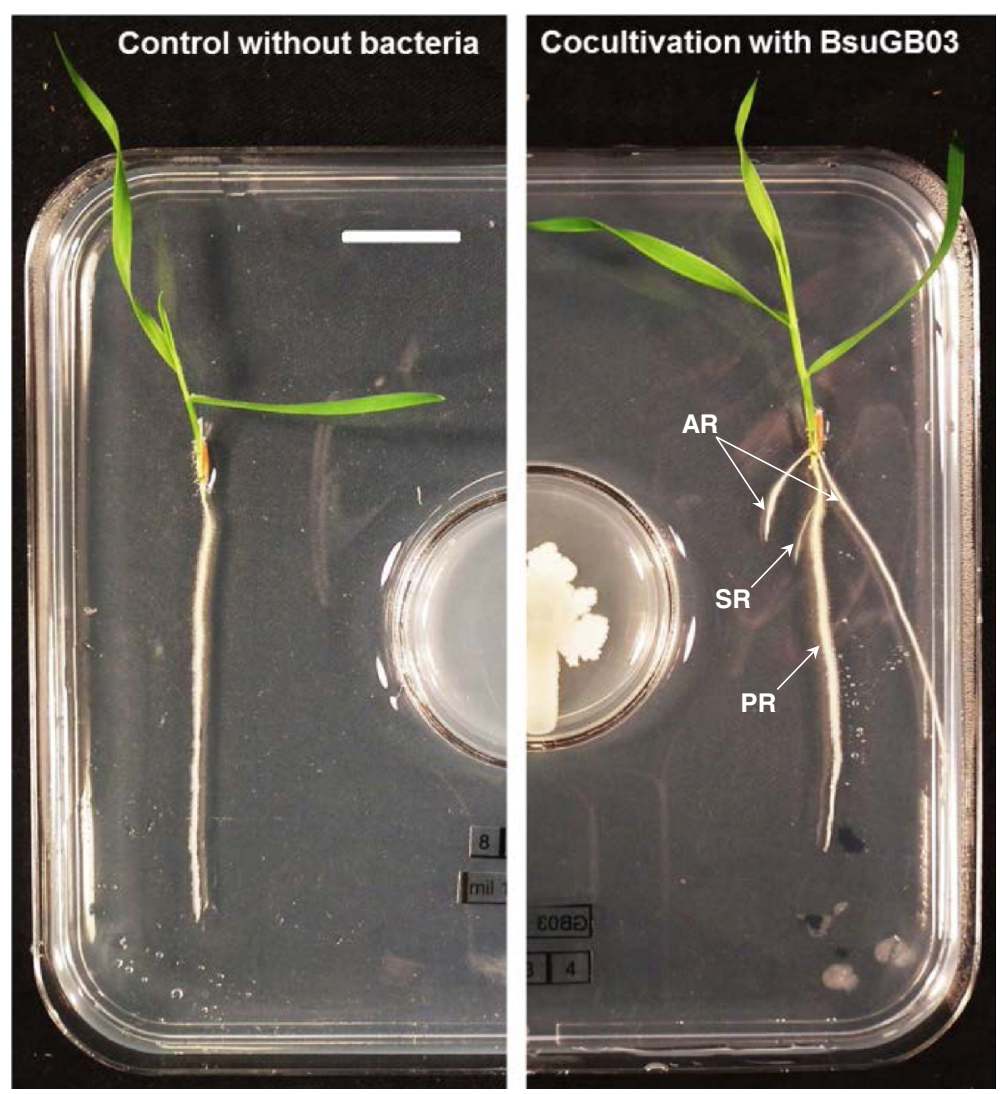

Fig. 1 In vitro co-cultivation system. B. distachyon Bd21 plantlets were photographed after 10 days of near-vertical growth without (left) or with (right) exposure to BsuGB03 volatiles. The bacterial compartment contains a Farag et al. [15] medium and the plant compartment contains a Hoagland agar plate. Both growing media are physically separated, which limits plant-bacteria interactions to the exchange of volatiles. The scale bar is $1.75 \mathrm{~cm}$ long. The arrows point the adventitious roots (AR), the secondary roots (SR) and the primary root (PR) locations 

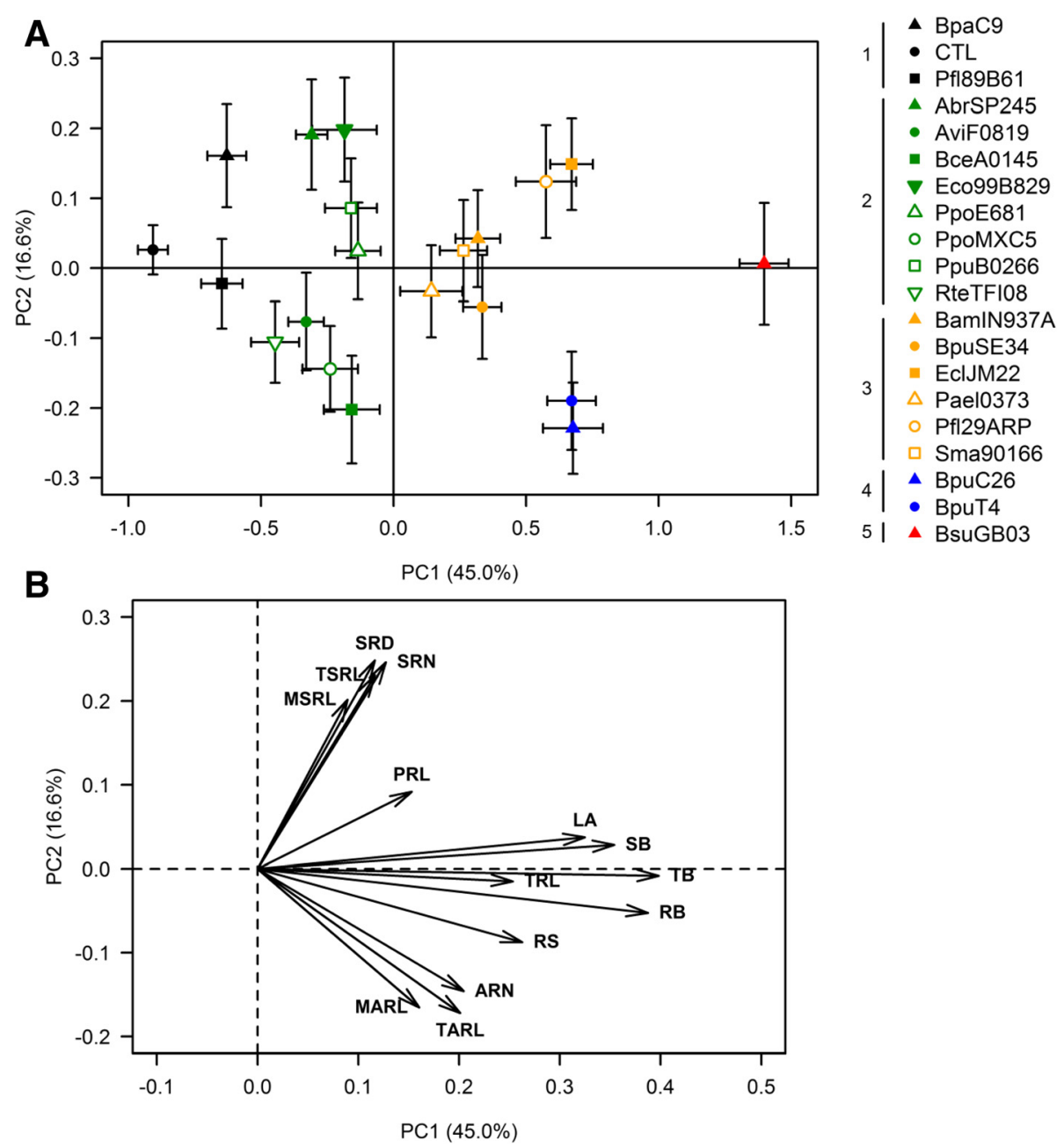

Fig. 2 PCA based on individual weighted and reduced data (a) and correlation circle between the 14 measured variables and the two first components of the PCA (b). Presented values are means of 64 or 128 biological replicates $+/-$ standard error of the mean for each strain and the control, respectively. Each of the five clusters defined by the hierarchical clustering processing is presented in a different colour: cluster 1, (including the control) black; 2 , green; 3, yellow; 4, blue; and 5, red. PC 1 is correlated mainly with the biomass production of the plantlets exposed to the bacterial volatile compounds, whereas PC2 is related to RSA modulation. The proportion of the total variance explained by the two first axes is $61.6 \%$

Axes 1 and 2 account for $61.6 \%$ of the total variance. Axis 1 is positively correlated with the growth-promotion ability of the strains, namely the total biomass (TB), root biomass (RB), shoot biomass (SB), leaf area (LA) and total root length (TRL) values (Fig. 2b). In contrast, axis 2 is related to RSA modulation and is positively correlated with secondary root growth (secondary root number (SRN), total secondary root length (TSRL), mean secondary root length (MSRL) and secondary root density (number of secondary roots per $\mathrm{cm}$ of primary root, SRD)) and negatively correlated with adventitious root growth (adventitious root number (ARN), total adventitious root length (TARL) and mean adventitious root length (MARL)).

Based on the PC values, the clustering algorithm allowed us to define five clusters of strains that induced consistent changes in the plantlet phenotypes (Fig. 3).
Cluster 1 contained strains that did not affect plant phenotype significantly compared with the control. Only three Cluster 2 strains slightly increased biomass production, but the overall effect was not significant. The Cluster 2 strains effects on the root branching process were variable. Strains in clusters 3 and 4 greatly increased biomass production, but had variable effects on RSA. Cluster 5 contained only one strain, which had the greatest growth-promotion ability (Fig. 3a).

\section{Cluster composition (Fig. 2a)}

Cluster 1 contained BpaC9 and Pfl89B61 in addition to the control (growth medium without bacteria). Cluster 2 had eight strains belonging to seven species and grouped into two sub-groups: (1) AbrSP245, Eco99B829, PpoE681, PpuB0266 with positive PC2 values; and (2) AviF0819, 

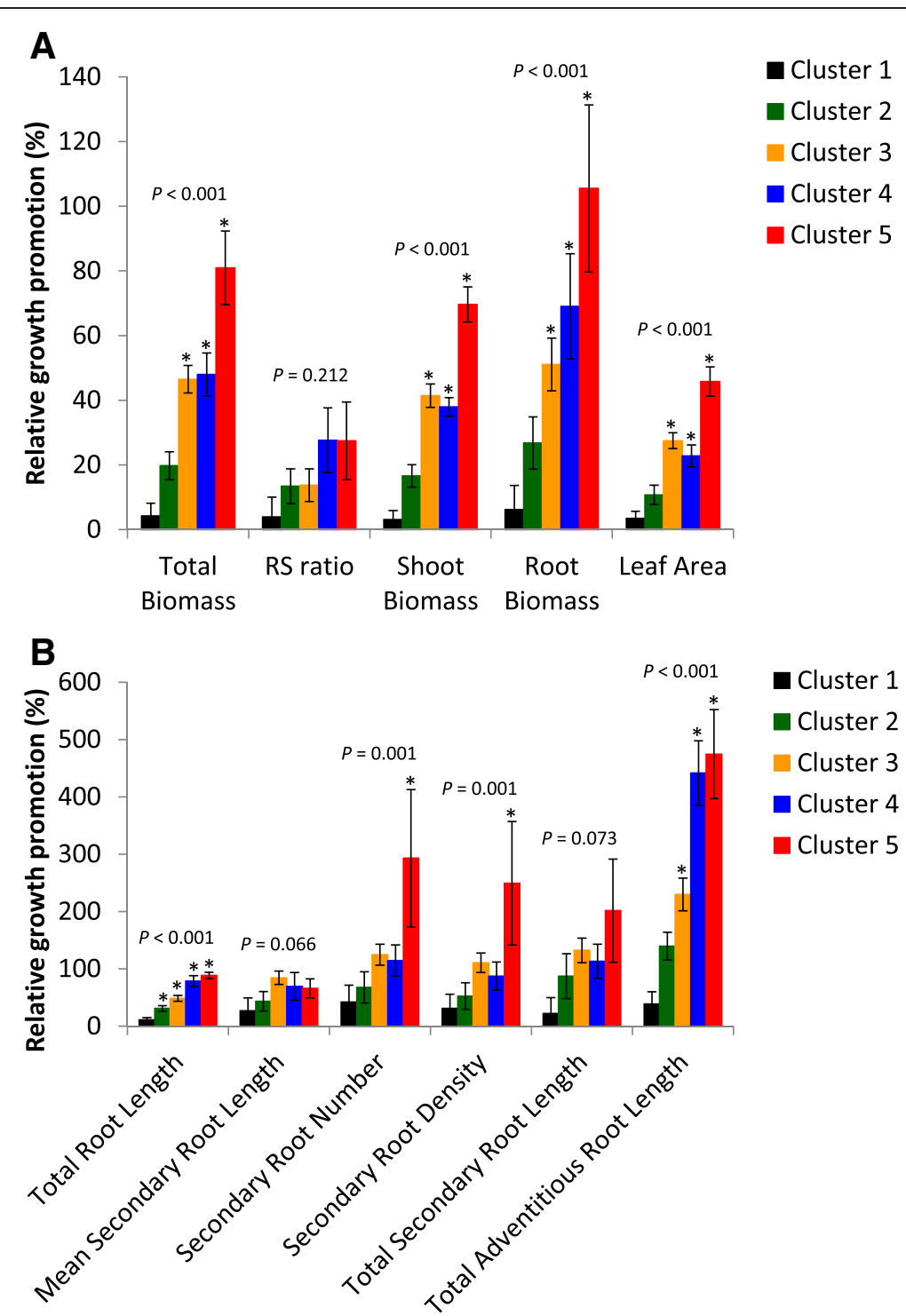

Fig. 3 Relative growth promotion effects (\%) on biomass (a) and RSA (b) variables. Each presented value is the mean of the relative differences between the replicates of the strains within a given cluster and the control without bacteria $+/$ - standard error of the mean. RSA parameters with the five highest correlation coefficients to PC1 and PC2 are presented. The $P$-values are displayed on the graphs. Significant changes compared with the control without bacteria are marked with an asterisk (*)

BceA0145, PpoMXC5 and RteTFI08 with negative PC2 values. Among the strains in cluster 3, most of them (BamIN937A, BpuSE34, EclJM22, PaeI0373, Pfl29ARP and Sma90166) had low positive PC1 values. BpuC26 and BpuT4 defined cluster 4. The only strain belonging to cluster 5 was BsuGB03.

Each cluster was further characterised according to its relative growth-promotion effects on biomass and RSA variables (Fig. 3a and b, respectively). For each variable, the cluster effect was expressed as the mean of the relative differences between the replicates of the strains within a given cluster and the control without bacteria.
Main volatile compound-mediated modulations of biomass production (Fig. 3a)

With regard to biomass production, the control plantlets had a TB of $34.1 \mathrm{mg}$ associated with a root-to-shoot ratio (RS) value of 0.50 (Fig. $4 \mathrm{a}$ ). Relative to the control, the plantlets exposed to the volatiles emitted by the cluster 1 strains showed no significant increase $(\max +6.2 \%$ for $\mathrm{RB}$ ) in any of the measured parameters. The overall increase in TB $(+19.7 \%)$, due mainly to root growth promotion $(+26.8 \%)$, induced by Cluster 2 strains was not significant. The increases in $\mathrm{TB}$ observed in clusters 3 and 4 were high $(+46.5$ and $+48 \%$, respectively), but 


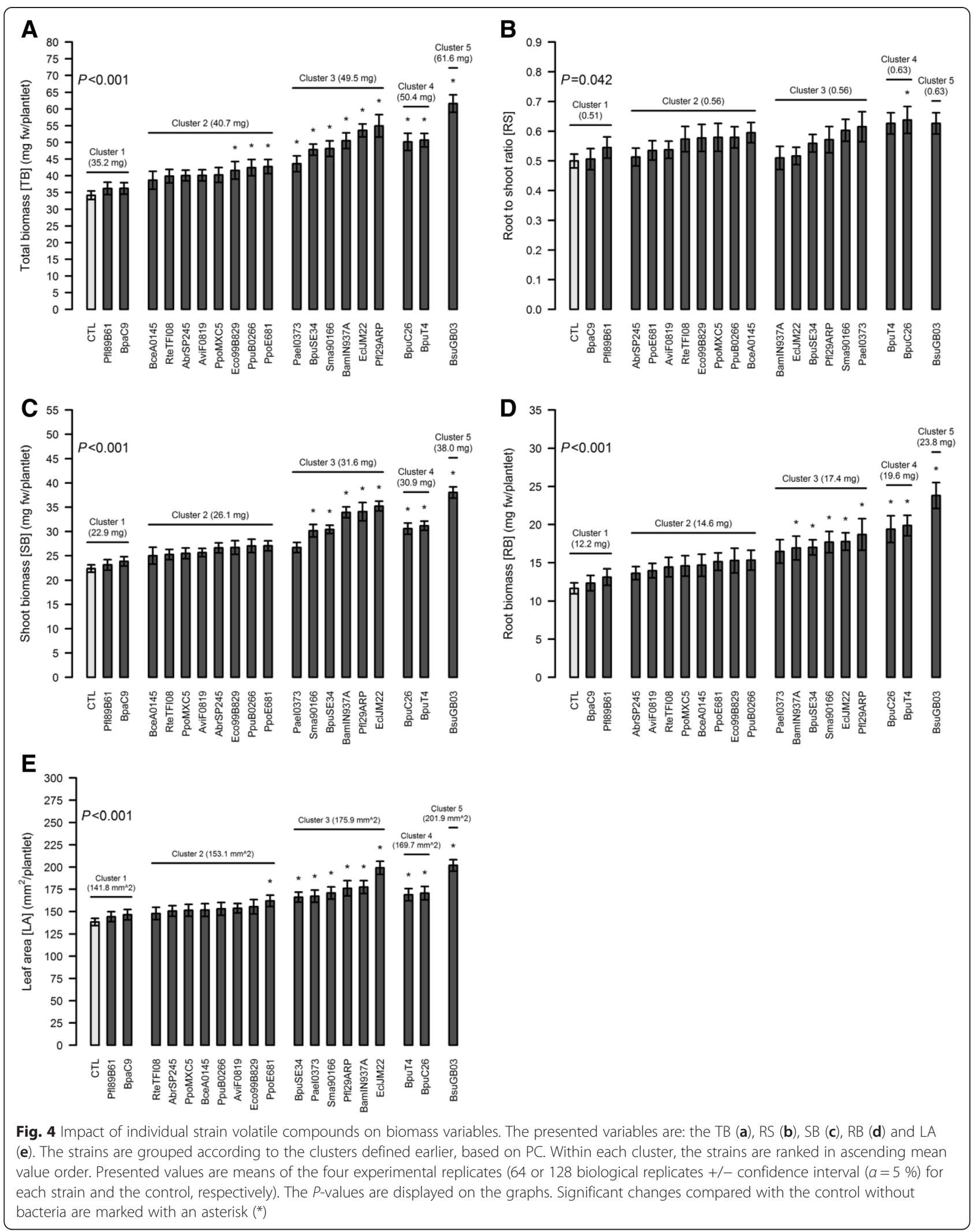


the plantlets in these clusters differed in terms of biomass allocation. Indeed, Cluster 4 strains induced a higher increase in RB (+69 \%). Cluster 5 had the highest increase in biomass production $(+80.9 \%$ increase in TB), its RS shift (+27.5\%) being very similar to the cluster 4 value. It is worth noting that the RB production of cluster 5 represented $205.5 \%$ of the control level $(+105.5 \%$, Fig. 3a). Finally, LA was increased by $45.8 \%$ in cluster 5. This trait is proportional to SB production for all the defined clusters.

\section{Biomass modulation potential of individual strains}

Apart from identifying the main grass plant phenotypes modulated by bacterial volatiles exposure, this study also sought to screen individual strains for their growthpromotion ability (Fig. 4).

$\mathrm{TB}$ is very significantly modulated by bacterial volatiles $(P<0.001)$. Out of the 19 strains, 12 induced a significant increase in TB production (Fig. 4a), ranging from $41.6 \mathrm{mg}$ (Eco99B829) to $61.6 \mathrm{mg}$ (BsuGB03). As stated earlier, no significant effect was noted for Pfl89B61 and BpaC9 (cluster 1 strains) and this was also the case for all the considered variables.

Only three out of eight cluster 2 strains induced a significant increase in TB production: Eco99B829, PpuB0266 and PpoE681. All three belong to the same sub-group and are characterised by positive $\mathrm{PC} 2$ values. All the other biomass-related traits remained unaffected within this cluster, apart from LA for only one strain (PpoE681, Fig. 4e). Due to its narrow $\mathrm{PC} 1$ positioning (Fig. 2), cluster 2 showed low intra-cluster variability for biomass production, whatever the variable.

In contrast, cluster 3 strains were more spread out on the $\mathrm{PC} 1$ axis and therefore presented greater heterogeneity, with the TB ranging from $43.6 \mathrm{mg}$ (PaeI0373) to $54.9 \mathrm{mg}$ (Pfl29ARP). All six of these strains showed a significant ability to increase TB and LA and only those plantlets exposed to PaeI0373 volatiles did not show any significant changes in SB and RB (Fig. 4c and d, respectively). As observed for cluster 2 strains, individual RS values remained statistically unaffected by all six strains (Fig. 4b).

The cluster 4 strains (BpuC26 and BpuT4) had similar effects on biomass production and both of them increased TB, SB, RB and LA. Compared with clusters 1, 2 and 3, these strains induced higher RB production, leading to a higher mean RS value (0.63), but BpuC26 was the only strain out of all 19 that was able to change RS significantly. Cluster 5's single Bacillus subtilis strain (BsuGB03) induced the highest TB, SB and RB production (61.6 $\mathrm{mg}, 38.0 \mathrm{mg}$ and $23.8 \mathrm{mg}$, respectively) without significantly affecting the RS value compared with the control.

\section{Main volatile-mediated modulations of root system architecture (RSA)}

With regard to RSA, the most correlated variables to PC1 and $\mathrm{PC} 2$ were selected to characterise each strain group (Fig. 3b). The control plantlets presented a TRL of $7.6 \mathrm{~cm}$, with limited secondary $(S R N=0.8 ; T S R L=0.5 \mathrm{~cm})$ or adventitious root production $(T A R L=1 \mathrm{~cm})$. SRD was therefore limited to 0.1 secondary root $\mathrm{cm}^{-1}$ of primary root (Fig. 5, Additional file 1: Figure S1). Cluster 1 showed no significant increase either in biomass production or RSA parameters. Unlike biomass production, Cluster 2 strains were able to induce a $30.8 \%$ overall increase in TRL. The RSA modulation ability of clusters 3 and 4 was consistent with their respective RS values. Both clusters greatly promoted total biomass production, but the TRL increase in cluster 3 was limited to $48.4 \%$, compared with a $78.7 \%$ increase in cluster 4 . The TARL increase was higher in cluster $4(+441.5 \%)$ than in cluster $3(+229.7 \%)$. Cluster 5 had the highest increase in TRL $(+88.5 \%)$, due almost entirely to increases in TARL $(+474.5 \%)$ and SRN (+293\%) compared with the control without bacteria. The MSRL increase (+65.9\%) was not significant.

\section{Modulation of the root system architecture (RSA) by individual strains}

Overall, the variability in the RSA parameters was higher than that of the biomass variables, apart from TRL and primary root length (PRL, Fig. 5). None of the cluster 1 strains induced significant changes in RSA variables.

With regard to cluster 2 strains, only BceA0145 induced significant changes in TRL, ARN and MARL (Fig. 5a, e and $\mathrm{f}$ ). Therefore, it is mostly responsible for the aforementioned overall cluster 2 significant change in TRL. None of these strains affected PRL, SRN or MSRL significantly (Fig. 5b, c and d). It should be noted that PC2positive strains showed the highest SRN and MSRL within this cluster. Apart from RteTFI08, the same was true for PC2-negative ones with regard to ARN and MARL. Four out of six strains increased TRL in cluster 3. In contrast, BamIN937A and Sma90166 did not induce significant change in TRL and gave the lowest MSRL and MARL values. In addition, BamIN937A volatiles seemed to slightly reduce PRL $(5.6 \mathrm{~cm})$ compared with the control $(6.1 \mathrm{~cm})$. This negative effect of BamIN937A volatiles on PRL was balanced by an average SRN (1.9) and a high ARN (1.7). The only cluster 3 strain that increased PRL was EclJM22 $(6.8 \mathrm{~cm})$. At the cluster 3 level, no statistically significant effect was measured for SRN and MSRL. All cluster 3 strains increased ARN, apart from PaeI0373. This strain, together with BpuSE34, induced the production of significantly longer adventitious roots (Fig. 5f). Both ARN and MARL showed high intra-cluster variability, ranging from 1.0 to 1.7 and from 1.6 to $2.9 \mathrm{~cm}$ plantlet ${ }^{-1}$, respectively. 

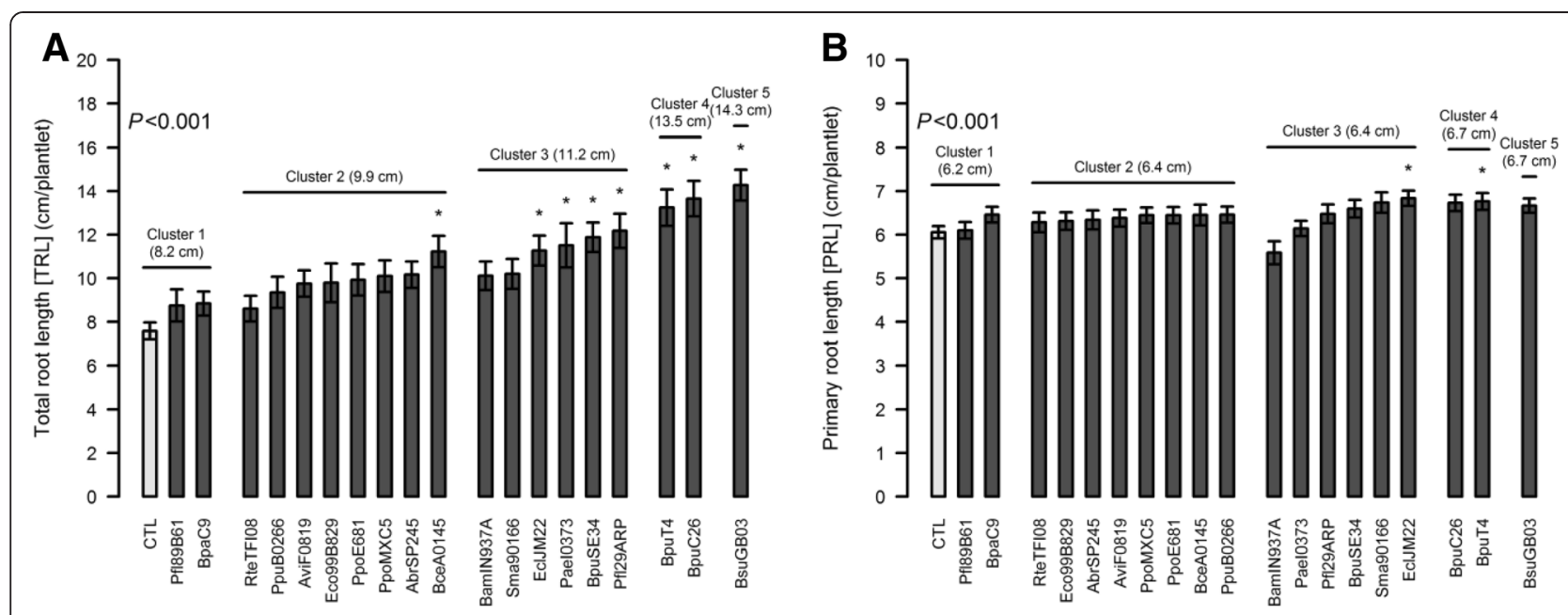

C

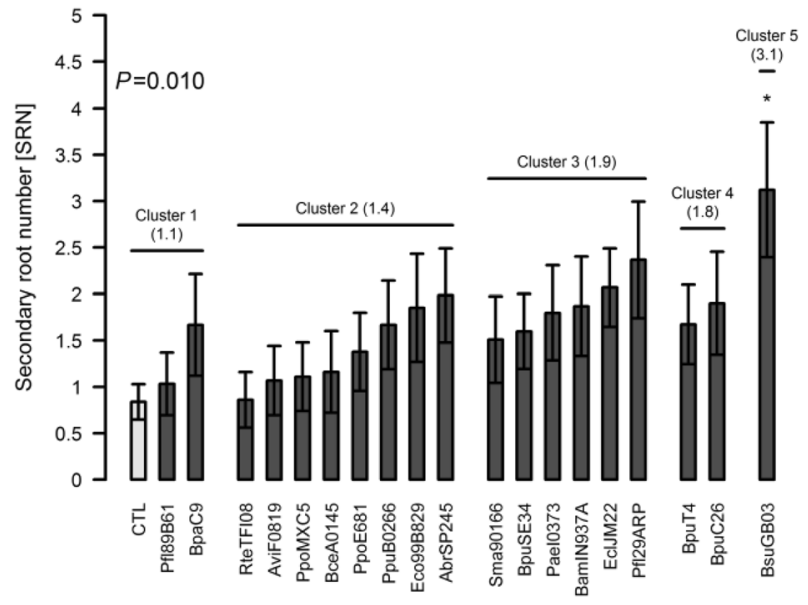

D

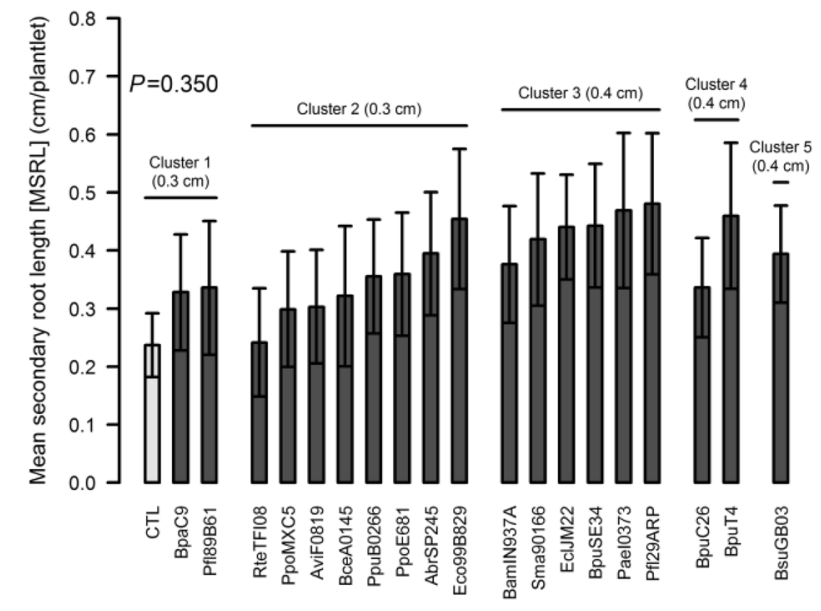

E

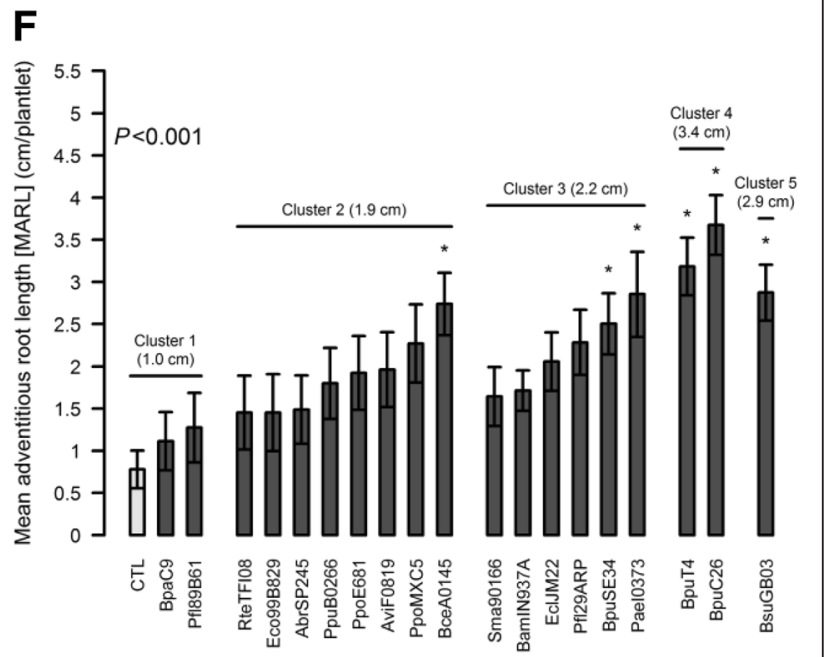

Fig. 5 Impact of individual strain volatile compounds on the main RSA variables. The presented variables are the TRL (a), PRL (b), SRN (c), MSRL (d), ARN (e) and MARL (f). The strains are grouped according to the clusters defined earlier, based on PC. Within each cluster, the strains are ranked in ascending mean value order. Presented values are means of the four experimental replicates (64 or 128 biological replicates $+/-$ confidence interval ( $a=5 \%)$ for each strain and the control, respectively). The $P$-values are displayed on the graphs. Significant changes compared with the control without bacteria are marked with an asterisk $\left(*^{*}\right)$ 
Cluster 4 strains increased TRL, ARN and MARL, but had no significant effect on SRN and MSRL. On average, contrary to secondary root traits, cluster 4 strains promoted adventitious root growth more effectively than cluster 3 strains did. Only BpuT4 significantly enhanced PRL $(6.8 \mathrm{~cm})$. As illustrated in Fig. 5b, this RSA parameter was one of the traits least affected by bacterial volatiles.

The cluster 5 strain (BsuGB03) had a significant impact on most RSA parameters, apart from PRL and MSRL. It induced the highest TRL $(14.3 \mathrm{~cm})$, explained mainly by high SRN and ARN values (3.1 and 2.0, respectively, $v s 0.8$ and 0.3 , respectively, for the control without bacteria).

\section{Correlations between biomass production and root system architecture (RSA) traits}

In our experiment, TB production was correlated mainly with TRL, SRN, ARN and SRD, with $r$ values ranging from 0.82 to 0.89 , and to a lesser extent with TSRL and TARL, with $r$ values of 0.72 and 0.75 , respectively. PRL was the RSA parameter least correlated $(r=0.41)$ with $\mathrm{TB}$ and it was not correlated with other RSA parameters either positively (generalised root growth promotion) or negatively (compensatory effect between primary root and secondary or adventitious root growth).

\section{Discussion}

\section{Bacterial volatiles have a significant impact on the early developmental stages of a model grass}

As shown in Fig. 1, representative plantlets subjected to BsuGB03 volatiles reached the 3-leaf stage (stage 13, [40]) after 10 days of co-cultivation, whereas control plantlets had only two unfolded leaves (stage 12). This observation is consistent with the results reported by [41], indicating that PGPR can induce significant changes in plant growth rate. This could also explain the observed RSA differences because $B$. distachyon plantlets are known to produce up to two coleoptile nodal adventitious roots at stage 13 [39]. In our in vitro system, TB production was strongly correlated with traits related to secondary and adventitious root growth. The correlation between TB production and PRL was weaker. Similar correlation results between TB and PRL, as well as TSRL, were observed for $A$. thaliana by [7], indicating that a branched root system phenotype seems to be associated with increased SB production.

Apart from BpuC26, the biomass allocation (RS) of the plantlets was not significantly influenced by bacterial volatiles. The observed growth-promotion effects therefore did not seem to be due to energy being used to increase root growth instead of shoot development.
Contrasting biomass and root system architecture (RSA) modulations define the five groups of bacterial strains The bacterial volatiles used in this study led to five groups of phenotypes being defined.

Group 1 strains (BpaC9 and Pfl89B61) did not cause any significant change after 10 days in either plant biomass production or RSA.

Three (Eco99B829, PpuB0266 and PpoE681) out of eight strains in Group 2 were able to increase plant total biomass significantly. This reflected altered root branching characterised by a higher SRN and MSRL.

Group 3 was characterised by high biomass production, but moderate impact on TRL. This group contained BamIN937A, BpuSE34, EclJM22, PaeI0373, Pfl29ARP and Sma90166, which were all able to promote plant growth significantly.

Group 4 contained two strains belonging to the same species and showing high growth-promotion potential: BpuC26 and BpuT4. They both induced a great increase in RB and TRL, which significantly affected biomass allocation for BpuC26.

The single strain in cluster 5, BsuGB03, showed the highest biomass production, with $\mathrm{RB}$ representing $205.5 \%$ of the control level. BsuGB03 induced the highest increase in TRL (+88.5\%), due almost entirely to increases in TARL (+474.5\%) and SRN (+293\%), without significantly affecting the growth of the primary root.

The plant growth modulation abilities of BsuGB03, BamIN937A, EclJM22, BpaC9, Pfl89B61 and Burkholderia cepacia were consistent with those observed by [6] and [11] on A. thaliana. The volatiles emitted by Sma90166, BpuT4, Eco99B829, Pseudomonas aeruginosa and Pseudomonas putida, however, improved $B$. distachyon biomass production without having any significant effect on $A$. thaliana growth $[6,11]$. The observed differences could be due to the receiving plant species or to technical constraints (e.g., bacterial and plant cultivation medium composition, Petri dish volume or inclination angle), resulting in different volatile concentrations and perceptions in the sealed system.

\section{Variability exists up to the intra-specific level and is not related to taxonomy}

Our results accord with the existing literature in that they suggest that the growth-promoting effect of particular strains is specific [7, 41]. With the bacterial volatile emission profiles differing at the genus, species and strain levels $[11,42]$, it is likely that their volatilemediated growth-promotion ability will vary. Strains belonging to the same species can induce fairly consistent plant growth promotion (e.g., Bacillus pumilus and Paenibacillus polymyxa strains) or have more variable 
effects on biomass production and RSA (e.g., Pseudomonas fluorescens strains).

Previous research on PGPR focused mainly on Gramnegative strains [7, 43, 44]. More recently, Bacillus strains have been tested for their growth-promoting ability [7]. In the present study, our strain selection included both Gram-positive and Gram-negative bacteria (Table 1). From a physiological point of view, most Gram-negative bacteria are unable to form spores [45]. This could affect their survival rate under natural adverse conditions or during formulation or storage prior to application [43]. Under our screening conditions, growth promotion was observed for both Gram-positive and Gram-negative strains, which is consistent with the results obtained on A. thaliana for BsuGB03 and EclJM22 [6]. Although cluster 4 and 5 strains belonged to the Gram-positive Bacillus genus, no clear trend appeared that would support the hypothesis that Gram-positive strains possess higher growth promotion ability. This point was emphasised by: (1) the cluster 3 and 2 strain composition; (2) the presence of a Bacillus strain (BpaC9) in the negative control cluster; and (3) the polyphyletic nature of bacterial groups based on Gram staining results $[46,47]$.

\section{Contrasting effects indicate some heterogeneity in bacterial volatile production}

The induced changes in the plantlet phenotypes varied greatly from one cluster to another. We hypothesize, therefore, that the volatile blends emitted by the bacteria were in line with this observation, both quantitatively (volatile concentrations) and qualitatively (volatile identities). This hypothesis has to be assessed based on a thorough analysis of the volatile emission kinetics of the strains used in the present study. Among the putative bioactive volatiles, the most important and prominent inorganic volatiles released by bacteria are ammonia (especially on a protein-rich medium), carbon dioxide and HCN. Moreover, 2,3-butanediol and its precursor, acetoin, are likely to be produced on the sucrosecontaining, low $\mathrm{pH}$ Murashige \& Skoog medium $[8,15]$. Microbes simultaneously produce 2,3-butanediol and $\mathrm{CO}_{2}$ from pyruvate by a fermentation process that involves the synthesis of the volatile precursor, 3-hydroxy-2-butanone (acetoin) [30]. In vitro, the observed volatile-mediated growth-promotion effects could therefore be at least partially linked to $\mathrm{CO}_{2}$ emissions [13, 48]. A significant increase in $\mathrm{CO}_{2}$ concentration due to bacterial emission, however, was unlikely in our experiment because it was

Table 1 Characteristics of the bacterial strains used in the study. For each of the 19 strains, the acronym, Gram type, family, reported ecophysiological characteristics and bibliographical references are presented

\begin{tabular}{|c|c|c|c|c|}
\hline Strain & Acronym & $\begin{array}{l}\text { Gram } \\
\text { type }\end{array}$ & Family & Characteristics and references \\
\hline Azospirillum brasilense SP245 & AbrSP245 & - & Rhodospirillaceae & Associative microaerophilic diazotroph [63] \\
\hline Azotobacter vinelandii A60 - F08 19 & AviF0819 & - & Pseudomonadaceae & Free-living aerobic diazotroph [64] \\
\hline $\begin{array}{l}\text { Bacillus amyloliquefaciens AP278 - } \\
\text { IN937a }\end{array}$ & BamIN937a & + & Bacillaceae & \multirow{6}{*}{$\begin{array}{l}\text { Some strains are diazotrophic or facultative microaerophilic; } \\
\text { many Bacillus produce antibiotics }([4,6,15,27,65-67] \text {, } \\
\text { *newly isolated strain) }\end{array}$} \\
\hline Bacillus pasteurii AP277 - C9 & ВpaC9 & + & Bacillaceae & \\
\hline Bacillus pumilus AP280 - T4 & BpuT4 & + & Bacillaceae & \\
\hline Bacillus pumilus AP281 - SE34 & BpuSE34 & + & Bacillaceae & \\
\hline Bacillus pumilus C26* & BpuC26 & + & Bacillaceae & \\
\hline Bacillus subtilis AP305 - GB03 & BsuGB03 & + & Bacillaceae & \\
\hline Burkholderia cepacia A01-45 & BceA0145 & - & Burkholderiaceae & $\begin{array}{l}\text { Rarely diazotrophic, associative endophytic nitrogen fixer, } \\
\text { wheat PGPR [68] }\end{array}$ \\
\hline Enterobacter cloacae AP12 - JM22 & EcIJM22 & - & Enterobacteriaceae & PGPR [6] \\
\hline Escherichia coli DH5a 99B829 & Eco99B829 & - & Enterobacteriaceae & Bacterial control [6] \\
\hline Paenibacillus polymyxa AP294 - E681 & PpoE681 & + & Paenibacillaceae & \multirow{2}{*}{$\begin{array}{l}\text { Facultative microaerophilic, can produce phytohormones } \\
\text { analogs, suppress pathogens and solubilize organic phosphate } \\
([4,27] \text {, *newly isolated strain) }\end{array}$} \\
\hline Paenibacillus polymyxa MXC5* & РpoMXC5 & + & Paenibacillaceae & \\
\hline Pseudomonas aeruginosa 103-73 & Pael0373 & - & Pseudomonadaceae & \multirow{4}{*}{ Associative wheat PGPR [68] } \\
\hline Pseudomonas fluorescens AP2 - 89B61 & Pfl89B61 & - & Pseudomonadaceae & \\
\hline Pseudomonas fluorescens Pf29Arp & Pfl29ARP & - & Pseudomonadaceae & \\
\hline Pseudomonas putida KT2440 - B02 66 & PpuB0266 & - & Pseudomonadaceae & \\
\hline Raoultella terrigena Tfio8* & RteTFI08 & - & Enterobacteriaceae & Aerobic or facultatively anaerobic, ${ }^{*}$ newly isolated \\
\hline Serratia marcescens AP4 - 90166 & Sma90166 & - & Enterobacteriaceae & PGPR $[4,6,27]$ \\
\hline
\end{tabular}


sealed by $\mathrm{CO}_{2}$-permeable Parafilm * [11]. Experiments testing this hypothesis could be performed by either absorbing the $\mathrm{CO}_{2}$ with $\mathrm{Ba}(\mathrm{OH})_{2}$, measuring $\mathrm{CO}_{2}$ in the reaction vessel or performing the experiments without any seal. With regard to the other biologically-active bacterial volatiles [8, 16-19], their roles in the growth promotion of $B$. distachyon remain to be investigated. More specifically, the volatile impacts on targeted processes driving the primary, secondary (lateral) and adventitious (crown) root development should be studied. Indeed, it is well known that bacterial volatiles are able to modulate the main hormonal pathways $[4,6,20,21]$ and that both specific and shared hormonal pathways are involved in postembryonic root development [49-51].

\section{From in vitro conditions to the field}

The in vitro co-cultivation system used in this study enabled us to screen 19 bacterial strains for their volatilemediated plant growth-promotion ability over a 10-day co-cultivation period. The $B$. distachyon plantlets were grown on near-vertical agar plates alongside a bacterial inoculum developed on a Murashige \& Skoog medium that was supplemented with sucrose and tryptic soy agar [15]. Previous studies have demonstrated that VOC profiles and the growth promotion effects of bacterial volatiles could depend on inoculum size and cultivation medium composition [11]. Due to technical constraints related to the overnight growth of the 19 bacterial suspensions, our inoculum size was limited to $2 * 10^{6}$ colony-forming units $\left(20 \mu \mathrm{l}\right.$ of a $10^{8}$ colony-forming units $\mathrm{mL}^{-1}$ cell suspension), which is lower than the values used by [6] and [7]. The medium [15] used in this study was a Murashige \& Skoog-based medium that allowed all 19 strains to grow, while emitting a limited amount of VOCs itself (Farag M., pers. com.). It is worth noting that the inoculum dose did not influence results when nutrient-poor media such as Murashige \& Skoog or Angle media were used in other studies [11]. In addition, plant growth-promotion effects mediated by Bacillus volatiles were observed only when a Murashige \& Skoog medium was used to grow the bacteria as well as the plants [8]. So the observed effects of different bacterial volatiles on plant growth need to be qualified as being media dependent. The same holds true for the results of the present study.

Transposing obtained results to field conditions is not straightforward and remains challenging [52]. This is due partly to the technical constraints (e.g., Petri dish size and volume, near-vertical cocultivation system) that limit the duration of the plant cultivation process, and thus restricted the scope of the present study to early developmental stages. In the field, in order to optimize resource-use efficiency under agronomical conditions, the main root foraging zones should ideally be located in the resource-rich areas of the soil [53]. In the present study, the observed RSA modulations could have contributed to greater tolerance of transient or prolonged drought stress because of increased root branching in the soil upper layers (topsoil foraging) or, to a lesser extent, a longer primary root (deep soil foraging), respectively. Such root phenotypes could also help plants efficiently acquire either relatively immobile (P, K) or mobile $(\mathrm{N})$ nutrients [53-55]. Moreover, various constraints (e.g., endogenous soil microbial populations, soil composition, porosity and aeration, root rhizodeposition, etc.) may influence the bacterial growth and release of volatiles, hence modulating the outcome of the plantbacteria interactions mediated by volatile compounds under field conditions.

\section{Future prospects}

The volatile emission kinetics of the complete set of strains are now being characterised in order to identify volatile compounds/mixtures that promote $B$. distachyon growth. There are more than 770 bacterial VOCs in the SuperScent public database (http://bioinf-applied. charite.de/superscent/index.php?site1/4home, $[9,13])$ and about 1000 microbial VOCs from 350 bacterial and 80 fungal species in the ' $m V O C$ ' database (http://bioinformatics.charite.de/mvoc/, $[5,56])$. Once the active compounds have been identified, experiments closer to field conditions should be performed. On the one hand, B. distachyon plantlets could be exposed to the bacterial volatile blends based on an ex vitro set-up similar to the one designed by [48] or [19]. This would allow the plants to (1) perceive the volatile signature in the root system without directly exposing the whole plant to the volatile blend and (2) reach older developmental stages corresponding to a mature RSA. On the other hand, slow-release formulations of the VOC candidates like those used in integrated pest management [57] could be used to expose the root system to controlled VOC concentrations and assess their effects in real soil conditions. Indeed, the VOC diffusion rate from their release point could be influenced by their polarity and the physico-chemical characteristics of the soil matrix $[12,13]$.

\section{Conclusions}

To the best of our knowledge, this study is the first report on bacterial volatile-mediated growth promotion of a grass plant. Using an in vitro near-vertical screening setup, five groups of strains inducing characteristic changes in a $B$. distachyon phenotype were defined. Contrasting modulations of biomass production coupled with changes in RSA were observed. Most of the strains that increased total plant biomass also modulated adventitious root growth. Under our screening conditions, total biomass production was strongly correlated with the length and 
branching of the root system components, except for primary root length. Irrespective of the considered phenotypic variables, B. subtilis GB03's volatile compounds induced the most significant changes. Considering the great diversity of bacterial volatile production, further experiments are needed to characterise the inorganic and organic volatile emission kinetics of these bacterial strains in order to identify the candidates responsible for the observed growth-promotion effects and to assess their influence on plant growth under agricultural soil conditions.

\section{Methods}

\section{Plant material}

Brachypodium distachyon (line $\mathrm{Bd} 21$ ) caryopses were kindly provided by Dr Philippe Vain from the John Innes Centre (Norwich, UK) and propagated under greenhouse conditions in 2009.

\section{Bacterial strains}

The bacterial strains used in the present study were selected based on their potential PGPR properties and/or their role in the nitrogen cycle (Table 1). Bacillus amyloliquefaciens In937A (BamIN937A), Bacillus pasteurii C9 (BpaC9), Bacillus pumilus T4 (BpuT4), Bacillus pumilus SE34 (BpuSE34), Bacillus subtilis GB03 (BsuGB03), Enterobacter cloacae JM22 (EclJM22), Escherichia coli DH5a 99B829 (Eco99B829), Paenibacillus polymyxa E681 (PpoE681), Pseudomonas fluorescens 89B61 (Pfl89B61) and Serratia marcescens 90166 (Sma90166) were kindly provided by Dr Paul W. Paré and Dr John McInroy (Texas Tech University, Lubbock, TX, USA). Pseudomonas fluorescens 29ARP (Pfl29ARP) was kindly provided by Dr Alain Sarniguet (Institut National de la Recherche Agronomique, Rennes, France). Azospirillum brasilense SP245 (AbrSP245), Azotobacter vinelandii F0819 (AviF0819), Bacillus pumilus C26 (BpuC26), Burkholderia cepacia A01-45 (BceA0145), Paenibacillus polymyxa MXC5 (PpoMXC5), Pseudomonas aeruginosa I03-73 (PaeI0373), Pseudomonas putida KT2440-B0266 (PpuB0266) and Raoultella terrigena Tfi08 (RteTFI08) came from the Katholieke Universiteit Leuven collection (Leuven, Belgium).

The main characteristics of these bacterial strains, including acronyms used in the study, Gram type and taxonomic position, are presented in Table 1.

\section{In vitro screening}

Brachypodium distachyon plantlets and bacterial strains were co-cultivated in vitro for 10 days at $22{ }^{\circ} \mathrm{C}$ in a system combining a $12-\mathrm{cm}$ square Petri dish (plant compartment) with the bottom part of a $3.5-\mathrm{cm}$ round one (bacterial compartment) in order to allow interactions throughout the gaseous phase only (Fig. 1).
The caryopses were surface-sterilised, as described by [58] and [59]. After $2 \mathrm{~h}$ of incubation in distilled water at room temperature, lemmas were removed and the grains were stored in distilled water. They were then successively incubated for $30 \mathrm{~s}$ in $70 \% \mathrm{v} / \mathrm{v}$ ethanol, rinsed once in sterile distilled water and surface-sterilised for $4 \mathrm{~min}$ in $1.4 \% \mathrm{v} / \mathrm{v}$ sodium hypochlorite solution under manual agitation, before being washed three times with sterile distilled water. The caryopses were stratified in the dark for 2 days at $4{ }^{\circ} \mathrm{C}$ on $0.8 \% \mathrm{w} / \mathrm{v}$ plant agar (Duchefa Biochemie B.V., Haarlem, The Netherlands) plates containing $1 \times$ Hoagland's medium $\left(6 \mathrm{mM} \mathrm{KNO}_{3}, 4 \mathrm{mM} \mathrm{Ca}\left(\mathrm{NO}_{3}\right)_{2}\right.$, $2 \mathrm{mM} \mathrm{MgSO}_{4}, 1 \mathrm{mM} \mathrm{NH}_{4} \mathrm{H}_{2} \mathrm{PO}_{4}, 17.97 \mu \mathrm{M}$ ferric tartrate. $2 \mathrm{H}_{2} \mathrm{O}, \quad 46.25 \mu \mathrm{M} \quad \mathrm{H}_{3} \mathrm{BO}_{3}, 9.15 \mu \mathrm{M} \quad \mathrm{MnCl}_{2} .4 \mathrm{H}_{2} \mathrm{O}$, $0.77 \mu \mathrm{M} \mathrm{ZnSO}{ }_{4} .7 \mathrm{H}_{2} \mathrm{O}, 0.32 \mu \mathrm{M} \mathrm{CuSO}_{4} .5 \mathrm{H}_{2} \mathrm{O}, 0.11 \mu \mathrm{M}$ $\mathrm{NaMoO}_{4} \cdot 2 \mathrm{H}_{2} \mathrm{O}$, Ref. 30630037-1, Plantmedia, Dublin, $\mathrm{OH}, \mathrm{USA}$ ), before being transferred for $24 \mathrm{~h}$ at $22{ }^{\circ} \mathrm{C}$ under $94 \mu \mathrm{mol} \mathrm{m}{ }^{-2} \mathrm{~s}^{-1}$ in the PAR (LED lighting) with a 20-h photoperiod, in line with the BrachyTAG culture protocol $[58,59]$. The caryopses were positioned on top of the agar plate, the embryo facing the Petri dish cover. The dishes were inclined at a $65^{\circ}$ angle to ensure proper root growth on top of the agar plates [7].

One week before the onset of the co-cultivation, each bacterial strain was freshly plated from its $20 \% \mathrm{v} / \mathrm{v}$ glycerol stock suspension stored at $-80{ }^{\circ} \mathrm{C}$. All the aforementioned strains were plated on $4 \% \mathrm{w} / \mathrm{v}$ tryptic soy agar (Sigma-Aldrich, Saint-Louis, MO, USA), apart from (1) Pfl29ARP and AviF0819, which were plated on $2.5 \% \mathrm{w} / \mathrm{v}$ lysogeny broth (Sigma-Aldrich) containing $1.5 \% \mathrm{w} / \mathrm{v}$ agar for microbiology (Sigma-Aldrich) and (2) AbrSP245 and BceA0145, which were grown on modified lysogeny broth agar supplemented with $2.5 \mathrm{mM} \mathrm{CaCl}_{2}$ and $2.5 \mathrm{mM} \mathrm{MgSO}$. The strains were plated again on their corresponding media $24 \mathrm{~h}$ before starting the overnight cultures in liquid medium ([15] $1 \times$ Murashige \& Skoog medium [Duchefa Biochemie B.V.], complemented with $1.5 \%$ sucrose and $0.4 \%$ tryptic soy broth [Sigma-Aldrich]). Each strain concentration was subsequently adjusted to $10^{8}$ colony-forming units $\mathrm{mL}^{-1}$ before the start of the co-cultivation step.

After $24 \mathrm{~h}$ of germination at $22{ }^{\circ} \mathrm{C}$, two $\mathrm{B}$. distachyon plantlets were transferred to each square 12-cm Petri dish containing $45 \mathrm{~mL}$ of Hoagland's medium (Plantmedia). Then $20 \mu \mathrm{L}$ of each bacteria suspension were pipetted in the bacterial compartment containing $3 \mathrm{~mL}$ of [15] medium (1× Murashige \& Skoog medium supplemented with $1.5 \% \mathrm{w} / \mathrm{v}$ agar for microbiology [Sigma-Aldrich], $1.5 \%$ sucrose and $0.4 \%$ tryptic soy agar [Sigma-Aldrich]). The bacterial suspension droplet was dried under a laminar flow before the 12-cm Petri dish was sealed with Parafilm (Pechiney Plastic Packaging Company, Chicago, IL, USA; [6]). The resulting co-cultivation dishes allowed the growth of the plantlets over 10 days in the presence of 
the bacteria at $22{ }^{\circ} \mathrm{C}$ under $94 \mu \mathrm{mol} \mathrm{m}{ }^{-2} \mathrm{~s}^{-1}$ in the PAR (LED lighting) with a 20-h photoperiod. Four independent experimental replicates were performed. Within each experiment, 16 plantlets were considered for each strain, and 32 plantlets were used for the control without bacteria that contained only the [15] medium. At the end of the co-cultivation process, TB, SB, RB, RS, LA and nine RSA parameters were recorded.

\section{Leaf area (LA) measurements}

After 10 days of co-cultivation, the Petri dishes were opened to get rid of the condensation water and prepare the roots and leaves for data collection. Each Petri dish was photographed with a 10 megapixel Finepix HS10 camera (Fujifilm Holdings, Tokyo, Japan). Projected LA was measured for each plantlet using MVHimage software v8 (Global Systems Science, Boston, MA, USA), in line with the manufacturer's instructions.

\section{Root system architecture (RSA) analysis}

Each root system was manually untangled with a needle in order to separate intermingled lateral roots before scanning at 200 dpi on an HP Scanjet G4010 A4 scanner (Hewlett-Packard, Palo Alto, CA, USA). The resulting images were analysed with EZ-Rhizo software [60], in line with the manufacturer's instructions. Each output file was manually checked and edited in order to correct errors in the automatic detection of the roots. Secondary and adventitious roots smaller than $1 \mathrm{~mm}$ were discarded and not taken into account for the calculation of RSA parameters and multivariate analysis. For each plantlet, PRL, SRN, MSRL, TSRL, SRD (number of secondary roots per $\mathrm{cm}$ of primary root), ARN, MARL, TARL and TRL were recorded.

\section{Statistical analysis}

Multivariate and univariate statistical analysis were performed with R 3.0.3 software [61] running the FactoMineR package 1.25 [62]. Using the 14 measured variables, PCA was performed on data that were weighted, centred and scaled to zero mean and unit variance. This approach assigned the same total weight for biomass and RSA variable classes and limited the bias associated with the number of biomass-related variables compared with the number of recorded RSA parameters ( $5 v s$, respectively). Within each class of variables, each measured parameter had the same weight irrespective of its order of magnitude. The resulting 14 PCs were then used as input variables for hierarchical clustering based on the Euclidian distance and the Ward algorithm.

After verifying the overall application conditions based on Normal Q-Q (normality check) and Scale Location (equality of variance check) plots, each variable was subjected to a two-way analysis of variance (ANOVA) using the strains as the fixed factor, the four experimental replicates as the random factor and their interaction as the basis of comparison. When strain influence on a particular variable was significant $(\mathrm{p}<0.05)$, means were separated using Dunnett's test. In the figures, mean values that were significantly distinct from the control $(\alpha=5 \%)$ are marked with an asterisk (*).

\section{Availability of supporting data}

The data set supporting the results of this article is included within the article and its additional file.

\section{Additional file}

Additional file 1: Figure S1. Impact of individual strain volatile compounds on Total Secondary Root Length (A), Total Adventitious Root Length (B) and Secondary Root Density (C). The strains are grouped according to the clusters defined earlier, based on PC. Within each cluster, the strains are ranked in ascending mean value order. Presented values are means of the four experimental replicates (64 or 128 biological replicates $+/$ - confidence interval $(a=5 \%)$ for each strain and the control, respectively). Significant changes compared with the control without bacteria are marked with an asterisk $\left(^{*}\right)$. (DOCX 374 kb)

\section{Abbreviations}

ANOVA: Analysis of variance; AR: Adventitious root; ARN: Adventitious root number; LA: Leaf area; MARL: Mean adventitious root length; MSRL: Mean secondary root length; PC: Principal component; PCA: Principal component analysis; PGPR: Plant growth-promoting rhizobacteria; PR: Primary root; PRL: Primary root length; RB: Root biomass; RS: Root-to-shoot ratio; RSA: Root system architecture; SB: Shoot biomass; SR: Secondary root; SRD: Secondary root density; SRN: Secondary root number; TARL: Total adventitious root length; TB: Total biomass; TRL: Total root length; TSRL: Total secondary root length; VOC: Volatile organic compound.

\section{Competing interests}

The authors declare that they have no competing interests.

\section{Authors' contributions}

Conceived and designed the experiments: PD, SV. Performed the experiment: CB, MM, PD, SV. Analysed the data: BD, CB, MM, PD, YB. Contributed reagents/materials/bacterial strains/analysis tools: BD, SS, PdJ, YB. Wrote the paper: PD. Revised the paper: BD, CB, MM, PdJ, SS, SV, YB. All authors read and approved the final manuscript.

\section{Acknowledgements}

The authors thank Paul Paré (Texas Tech University, Lubbock, TX, USA), Richard Sibout (Institut National de la Recherche Agronomique, Versailles, France) and Micheline Vandenbol and Marc Ongena (Gembloux Agro-Bio Tech, Gembloux, Belgium) for their fruitful discussions. The authors also thank Adeline Blondiaux for her excellent technical assistance in setting up the in vitro co-cultivation system and producing the analysed dataset. We also thank Gerry Cambier for editing the English composition of the article. This work was financially supported by the Belgian Fonds de la Recherche Scientifique - FNRS (FRFC project 2.4.591.10.F and post-doctoral grant CTP 1808458). Delory B.M. (Research Fellow) is financially supported by the Belgian National Fund for Scientific Research (F.R.S.-FNRS).

\section{Author details}

'University of Liège, Gembloux Agro-Bio Tech, Plant Biology, Passage des Déportés 2, 5030 Gembloux, Belgium. ²Department of Plant Microbe Interactions, Max Planck Institute for Plant Breeding Research, Carl-von-Linné-Weg 10, 50829 Köln, Germany. ${ }^{3}$ University of Liège, Gembloux Agro-Bio Tech, Applied Statistics, Computer Science and Modeling, Passage des Déportés 2, 5030 Gembloux, Belgium. 
Received: 6 May 2015 Accepted: 3 August 2015

\section{Published online: 12 August 2015}

\section{References}

1. Bulgarelli D, Schlaeppi $K$, Spaepen $S$, Ver Loren van Themaat E, Schulze-Lefert P. Structure and functions of the bacterial microbiota of plants. Annu Rev Plant Biol. 2013;64:807-38.

2. Prashar P, Kapoor N, Sachdeva S. Rhizosphere: Its structure, bacterial diversity and significance. Rev Environ Sci Biotechnol. 2014;13:63-77.

3. Pii Y, Mimmo T, Tomasi N, Terzano R, Cesco S, Crecchio C: Microbial interactions in the rhizosphere: beneficial influences of plant growth-promoting rhizobacteria on nutrient acquisition process. A review. Biol Fertil Soils 2015, DOI 10.100.

4. Ryu C-M, Hu C-H, Locy RD, Kloepper JW. Study of mechanisms for plant growth promotion elicited by rhizobacteria in Arabidopsis thaliana. Plant Soil. 2005;268:285-92.

5. Peñuelas J, Asensio D, Tholl D, Wenke K, Rosenkranz M, Piechulla B, et al. Biogenic volatile emissions from the soil. Plant Cell Environ. 2014;37:1866-91.

6. Ryu C-M, Farag MA, Hu C-H, Reddy MS, Wei H-X, Paré PW, et al. Bacterial volatiles promote growth in Arabidopsis. Proc Natl Acad Sci U S A. 2003;100:4927-32.

7. Gutiérrez-Luna FM, López-Bucio J, Altamirano-Hernández J, Valencia-Cantero E, Cruz HR, Macías-Rodríguez L. Plant growth-promoting rhizobacteria modulate root-system architecture in Arabidopsis thaliana through volatile organic compound emission. Symbiosis. 2010;51:75-83.

8. Bailly $A$, Weisskopf $L$. The modulating effects of bacterial volatiles on plant growth. Current knowledge and future challenges. Plant Signal Behav. 2012:7(January):1-7.

9. Schulz S, Dickschat JS. Bacterial volatiles: the smell of small organisms. Nat Prod Rep. 2007:24:814-42.

10. Blom D, Fabbri C, Eberl L, Weisskopf L. Volatile-mediated killing of Arabidopsis thaliana by bacteria is mainly due to hydrogen cyanide. Appl Environ Microbiol. 2011;77:1000-8.

11. Blom D, Fabbri C, Connor EC, Schiestl FP, Klauser DR, Boller T, et al. Production of plant growth modulating volatiles is widespread among rhizosphere bacteria and strongly depends on culture conditions. Environ Microbiol. 2011:13:3047-58.

12. Wenke K, Kai M, Piechulla B. Belowground volatiles facilitate interactions between plant roots and soil organisms. Planta. 2010:231:499-506.

13. Wenke K, Weise T, Warnke R, Valverde C, Wanke D, Kai M, et al. Biocommunication of Plants. In: Witzany G, Baluška F, editors. Signaling and Communication in Plants. Volume 14. Berlin, Heidelberg: Springer Berlin Heidelberg; 2012. Signaling and Communication in Plants.

14. Vespermann A, Kai M, Piechulla B. Rhizobacterial volatiles affect the growth of fungi and Arabidopsis thaliana. Appl Environ Microbiol. 2007;73:5639-41.

15. Farag M, Ryu C-M, Sumner LW, Paré PW. GC-MS SPME profiling of rhizobacterial volatiles reveals prospective inducers of growth promotion and induced systemic resistance in plants. Phytochemistry. 2006;67:2262-8,

16. Zou C, Li Z, Yu D. Bacillus megaterium strain XTBG34 promotes plant growth by producing 2-pentylfuran. J Microbiol. 2010:48:460-6.

17. Velázquez-Becerra C, Macías-Rodríguez LI, López-Bucio J, Altamirano-Hernández J, Flores-Cortez I, Valencia-Cantero E. A volatile organic compound analysis from Arthrobacter agilis identifies dimethylhexadecylamine, an amino-containing lipid modulating bacterial growth and Medicago sativa morphogenesis in vitro. Plant Soil. 2011:339:329-40.

18. Weise T, Kai M, Piechulla B. Bacterial ammonia causes significant plant growth inhibition. PLoS One. 2013;8:e63538.

19. Park Y-S, Dutta S, Ann M, Raaijmakers JM, Park K: Promotion of plant growth by Pseudomonas fluorescens strain SS101 via novel volatile organic compounds. Biochem Biophys Res Commun 2015, in press:1-5.

20. Ryu C, Farag MA, Hu C, Reddy MS, Kloepper JW, Pare PW. Bacterial Volatiles Induce Systemic Resistance in Arabidopsis. Plant Physiol. 2004:134(March):1017-26.

21. Cho SM, Kang BR, Han SH, Anderson AJ, Park J, Lee Y, et al. 2R, 3RButanediol, a Bacterial Volatile Produced by Pseudomonas chlororaphis O6, Is Involved in Induction of Systemic Tolerance to Drought in Arabidopsis thaliana. Mol Plant-Microbe Interact. 2008;21:1067-75.

22. Zhang H, Sun Y, Xie X, Kim M-S, Dowd SE, Paré PW. A soil bacterium regulates plant acquisition of iron via deficiency-inducible mechanisms. Plant J. 2009:58:568-77.

23. Farag M, Zhang H, Ryu C-M. Dynamic chemical communication between plants and bacteria through airborne signals: induced resistance by bacterial volatiles. J Chem Ecol. 2013;39:1007-18.
24. Vacheron J, Desbrosses G, Bouffaud M-L, Touraine B, Moënne-Loccoz Y, Muller $\mathrm{D}$, et al. Plant growth-promoting rhizobacteria and root system functioning. Front Plant Sci. 2013;4(September):356.

25. Kwon YS, Ryu C-M, Lee S, Park HB, Han KS, Lee JH, et al. Proteome analysis of Arabidopsis seedlings exposed to bacterial volatiles. Planta. 2010;232:1355-70.

26. Xie X, Zhang H, Paré PW. Sustained growth promotion in Arabidopsis with long-term exposure to the beneficial soil bacterium Bacillus subtilis (GB03). Plant Signal Behav. 2009;4:948-53.

27. Ryu C, Farag MA, Paré PW, Kloepper JW. Invisible Signals from the Underground : Bacterial Volatiles Elicit Plant Growth Promotion and Induce Systemic Resistance. Plant Pathol J. 2005;21:7-12.

28. Cortes-Barco AM, Goodwin PH, Hsiang T. Comparison of induced resistance activated by benzothiadiazole, (2R,3R)-butanediol and an isoparaffin mixture against anthracnose of Nicotiana benthamiana. Plant Pathol. 2010;59:643-53.

29. Cortes-Barco A, Hsiang T, Goodwin PH. Induced systemic resistance against three foliar diseases of Agrostis stolonifera by (2R,3R)-butanediol or an isoparaffin mixture. Ann Appl Biol. 2010;157:179-89.

30. D'Alessandro M, Erb M, Ton J, Brandenburg A, Karlen D, Zopfi J, et al. Volatiles produced by soil-borne endophytic bacteria increase plant pathogen resistance and affect tritrophic interactions. Plant Cell Environ. 2014;37:813-26.

31. Kai M, Crespo E, Cristescu SM, Harren FJM, Francke W, Piechulla B. Serratia odorifera: analysis of volatile emission and biological impact of volatile compounds on Arabidopsis thaliana. Appl Microbiol Biotechnol. 2010;88:965-76.

32. Astrom B, Gerhardson B. Wheat cultivar reactions to deleterious rhizosphere bacteria under gnotobiotic conditions. Plant Soil. 1989;117:157-65.

33. Hochholdinger F, Park WJ, Sauer M, Woll K. From weeds to crops: genetic analysis of root development in cereals. Trends Plant Sci. 2004;9:42-8.

34. Ditengou FA, Müller A, Rosenkranz M, Felten J, Lasok H, van Doorn MM, et al. Volatile signalling by sesquiterpenes from ectomycorrhizal fungi reprogrammes root architecture. Nat Commun. 2015;6:6279.

35. Opanowicz M, Vain P, Draper J, Parker D, Doonan JH. Brachypodium distachyon: making hay with a wild grass. Trends Plant Sci. 2008;13(March):172-7.

36. Mochida K, Shinozaki K. Unlocking triticeae genomics to sustainably feed the future. Plant Cell Physiol. 2013:54:1931-50.

37. Catalan P, Chalhoub B, Chochois V, Garvin DF, Hasterok R, Manzaneda AJ, et al. Update on the genomics and basic biology of Brachypodium. International Brachypodium Initiative (IBI). Trends Plant Sci. 2014;19:414-8.

38. Girin T, David LC, Chardin C, Sibout R, Krapp A, Ferrario-Mery S, et al. Brachypodium: a promising hub between model species and cereals. J Exp Bot. 2014;65:5683-96.

39. Watt M, Schneebeli K, Dong P, Wilson IW. The shoot and root growth of Brachypodium and its potential as a model for wheat and other cereal crops. Funct Plant Biol. 2009:36:960.

40. Hong S-Y, Park J-H, Cho S-H, Yang M-S, Park C-M. Phenological growth stages of Brachypodium distachyon: codification and description. Weed Res. 2011;51:612-20.

41. Schwachtje J, Karojet S, Kunz S, Brouwer S, van Dongen JT. Plant-growth promoting effect of newly isolated rhizobacteria varies between two Arabidopsis ecotypes. Plant Signal Behav. 2012;7:623-7.

42. Kai M, Effmert U, Berg G, Piechulla B. Volatiles of bacterial antagonists inhibit mycelial growth of the plant pathogen Rhizoctonia solani. Arch Microbiol. 2007;187:351-60

43. Bashan Y, de Bashan LE, Prabhu SR, Hernandez J-P. Advances in plant growth-promoting bacterial inoculant technology: formulations and practical perspectives (1998-2013). Plant Soil. 2013;378:1-33.

44. Ahemad M, Kibret M. Mechanisms and applications of plant growth promoting rhizobacteria: Current perspective. J King Saud Univ - Sci. 2014;26:1-20.

45. Tocheva El, Dekas AE, McGlynn SE, Morris D, Orphan VJ, Jensen GJ. Polyphosphate storage during sporulation in the Gram-negative bacterium Acetonema longum. J Bacteriol. 2013;195(June):3940-6.

46. Woese CR. Bacterial Evolution Background. Microbiol Rev. 1987;51:221-71.

47. Gupta RS. Protein Phylogenies and Signature Sequences : A Reappraisal of Evolutionary Relationships among Archaebacteria, Eubacteria, and Eukaryotes. Microbiol Mol Biol Rev. 1998;62:1435-91.

48. Kai M, Piechulla B. Plant growth promotion due to rhizobacterial volatiles-an effect of CO2? FEBS Lett. 2009;583:3473-7.

49. Orman-Ligeza B, Parizot B, Gantet PP, Beeckman T, Bennett MJ, Draye X. Post-embryonic root organogenesis in cereals: branching out from model plants. Trends Plant Sci. 2013;18:459-67. 
50. Pérez-Montaño F, Alías-Villegas C, Bellogín RA, del Cerro P, Espuny MR, Jiménez-Guerrero I, et al. Plant growth promotion in cereal and leguminous agricultural important plants: From microorganism capacities to crop production. Microbiol Res. 2013;169:325-36.

51. Smith S, De Smet I. Root system architecture: insights from Arabidopsis and cereal crops. Philos Trans R Soc B Biol Sci. 2012;367:1441-52.

52. Meister R, Rajani MS, Ruzicka D, Schachtman DP. Challenges of modifying root traits in crops for agriculture. Trends Plant Sci. 2014;19:779-88.

53. Lynch JP. Steep, cheap and deep: an ideotype to optimize water and N acquisition by maize root systems. Ann Bot. 2013;112:347-57.

54. Pacheco-Villalobos D, Hardtke CS. Natural genetic variation of root system architecture from Arabidopsis to Brachypodium: towards adaptive value. Philos Trans R Soc Lond B Biol Sci. 2012:367:1552-8.

55. Tian X, Doerner P. Root resource foraging: does it matter? Front Plant Sci. 2013;4(August):303.

56. Piechulla B, Degenhardt J. The emerging importance of microbial volatile organic compounds. Plant Cell Environ. 2014;37:811-2.

57. Heuskin S, Verheggen FJ, Haubruge E, Wathelet J. The use of semiochemical slow-release devices in integrated pest management strategies. Biotechnol Agron Société Environ. 2011;15:459-70.

58. Vain P, Worland B, Thole V, McKenzie N, Alves SC, Opanowicz M, et al. Agrobacterium-mediated transformation of the temperate grass Brachypodium distachyon (genotype Bd21) for T-DNA insertional mutagenesis. Plant Biotechnol J. 2008;6:236-45

59. Alvès S, Worland B, Thole V, Snape J, Bevan M, Vain P. A protocol for Agrobacterium-mediated transformation of Brachypodium distachyon community standard line Bd21. Nat Protoc. 2009;4:638-49.

60. Armengaud P, Zambaux K, Hills A, Sulpice R, Pattison R, Blatt MR, et al. EZ-Rhizo: integrated software for the fast and accurate measurement of root system architecture. Plant J. 2009;57:945-56.

61. R: A language and environment for statistical computing. R Foundation for Statistical Computing, Vienna, Austria. URL http://www.r-project.org/ [http:// www.r-project.org/]

62. Husson F, Josse J, Le S, Mazet J: FactoMineR: Multivariate Exploratory Data Analysis and Data Mining with R. R package version 1.25. http://CRAN.Rproject.org/package=FactoMineR. 2013.

63. Kennedy IR, Choudhury ATMA, Kecskès ML. Non-symbiotic bacterial diazotrophs in crop-farming systems: can their potential for plant growth promotion be better exploited? Soil Biol Biochem. 2004;36:1229-44.

64. De Freitas JR, Germida JJ. A root tissue culture system to study winter wheat-rhizobacteria interactions. Appl Microbiol Biotechnol. 1990;33:589-95.

65. Zhang H, Kim M-S, Krishnamachari V, Payton P, Sun Y, Grimson M, et al. Rhizobacterial volatile emissions regulate auxin homeostasis and cell expansion in Arabidopsis. Planta. 2007:226:839-51.

66. Zhang H, Xie X, Kim M-S, Kornyeyev DA, Holaday S, Paré PW. Soil bacteria augment Arabidopsis photosynthesis by decreasing glucose sensing and abscisic acid levels in planta. Plant J. 2008;56:264-73.

67. Zhang H, Kim M-S, Sun Y, Dowd SE, Shi H, Paré PW. Soil bacteria confer plant salt tolerance by tissue-specific regulation of the sodium transporter HKT1. Mol Plant-Microbe Interact. 2008;21:737-44.

68. Walley FL, Germida JJ. Response of spring wheat (Triticum aestivum) to interactions between Pseudomonas species and Glomus clarum NT 4. Biol Fertil Soils. 1997;24:365-71.

\section{Submit your next manuscript to BioMed Central and take full advantage of:}

- Convenient online submission

- Thorough peer review

- No space constraints or color figure charges

- Immediate publication on acceptance

- Inclusion in PubMed, CAS, Scopus and Google Scholar

- Research which is freely available for redistribution 